\section{Battlefield insectica}

\section{Entomologists are briefing the military on how to protect troops from the scourge of the desert: sandflies. Rex Dalton reports.}

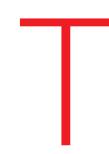

he desert to the east of Palm Springs, California, is heaven for entomologists. Between date-palm fields irrigated with standing water and the inland Salton Sea buzz a bonanza of insects. Researcher Kenneth Linthicum makes his way through the low scrub, which his team has sprayed in places with the insecticide bifenthrin. He checks traps that spew carbon dioxide, a lure for mosquitoes.

Linthicum is on a quest to battle these pesky creatures, particularly in vulnerable populations such as US troops stationed in Iraq and other desert areas. He is one of a handful of researchers on the front lines of an entomological battle, working to reduce the incidence of insect-borne diseases among the military. In particular, they are targeting the tiny sandfly (genus Phlebotomus), which transmits the protozoan that causes the sometimes deadly disease leishmaniasis.

Leishmaniasis is a major public-health concern: 12 million people are infected worldwide, with an estimated 2 million new infections each year. Military researchers have taken the lead before in developing insect repellants that end up benefiting civilians; DEET, for instance, was developed as a consequence of World War II jungle battles. Now, with troops in Iraq and Afghanistan, scientists are turning their attention to the little-understood plague of sandflies. "It's amazing we didn't know more about this bug," says Linthicum, who directs a US Department of Agriculture (USDA) research centre in Gainesville, Florida.

\section{Irritating bites}

When US troops invaded Iraq in 2003, soldiers woke regularly with a rash of highly irritating bites they called Baghdad boils. "Soldiers were getting eaten alive by the sandflies," says Russell Coleman, a medical epidemiologist with the US Army who was deployed with the first troops at Tallil airbase in southern Iraq. "In certain units, $70 \%$ were taking dozens to hundreds of bites a night." More than 1,450 US troops have contracted leishmaniasis in the past four years, mainly in Iraq and Afghanistan.

In 2004, the military established the Deployed War-Fighter Protection Program, with a particular focus on sandflies. It receives US $\$ 5$ million a year for projects overseen by the Armed Forces Pest Management Board in Washington, DC. agement board. it gets up five minutes later."

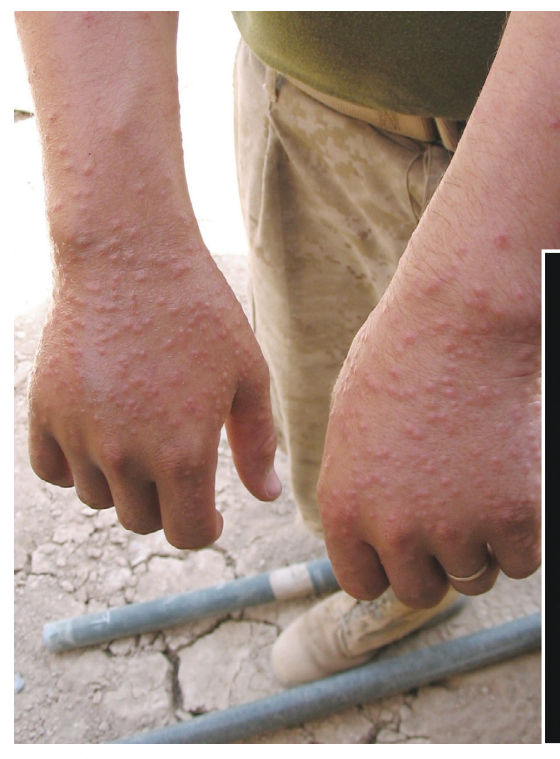

The programme includes scientists from all the services (Army, Navy, Air Force and Marines), along with academics and USDA researchers. They collaborate with military researchers from other countries, such as an Australian team who are studying ways to improve uniforms against insect bites ${ }^{2}$. "We are hoping to use the combined expertise to find new methods to protect personnel," says Stanton Cope, a Navy entomologist based in Washington DC, who serves as a point of liaison between the researchers and the pest-man-

\section{A uniform approach}

Leishmaniasis has two main forms: cutaneous, which creates skin lesions or attacks the mucous membranes, and internal or visceral, which can lead to liver and other organ problems and, in rare cases, death. Sandflies present a whole new challenge to military entomologists who are used to fighting mosquitoes. That's because the insecticide usually used on military clothing, permethrin, often isn't effective against the sandfly. "A mosquito may land on a uniform, bounce around, then fall dead from the insecticide," says Ulrich Bernier, a chemist working at the USDA's Gainesville centre. "A sandfly will be knocked out - then

Uniforms are the first line of defence against bug bites. In the past, they were made of wool

Bites (left) from the sandfly (right) expose US troops to the potentially deadly disease leishmaniasis.

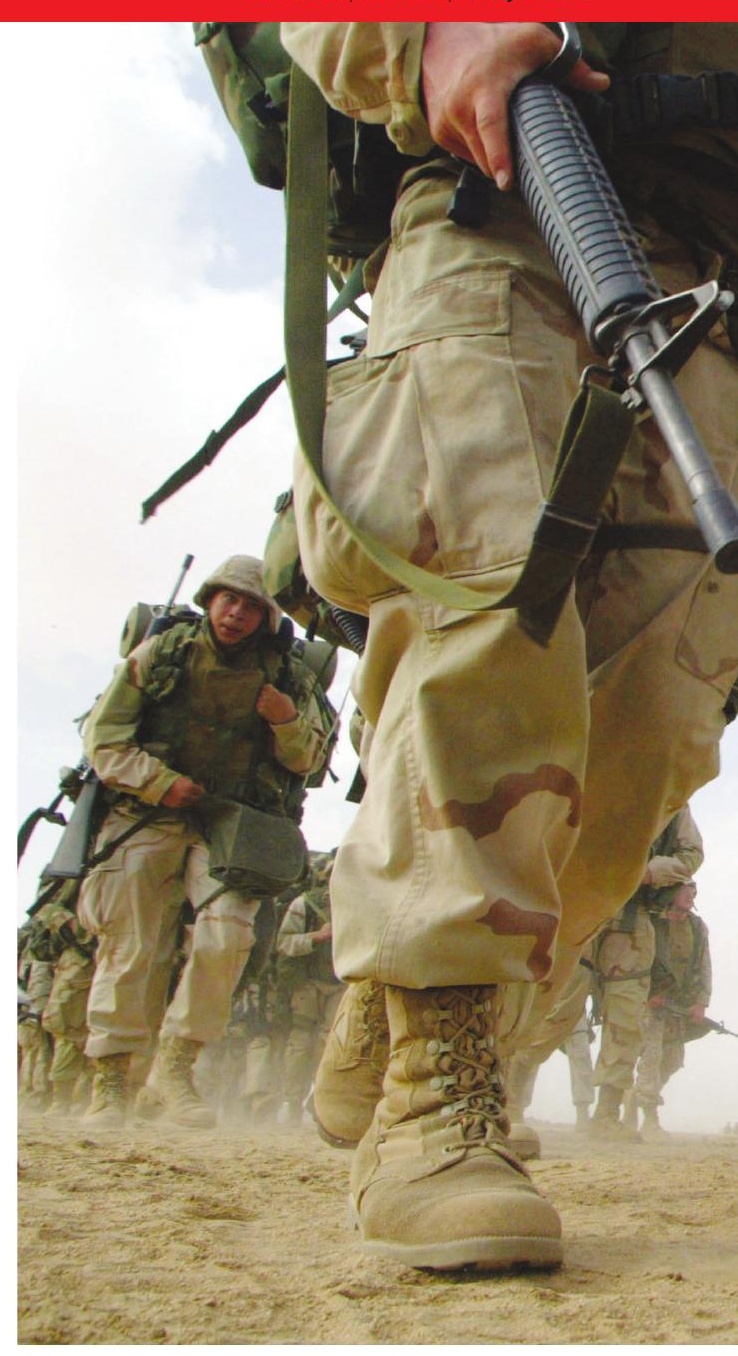

or cotton, with simple but durable weaves saturated in an insecticide such as permethrin. Today, uniforms have specially designed weaves of specific thickness in a mix of threads such as nylon, rayon and cotton to make them durable and protective. They are meant to protect against mosquitoes, ticks and fleas; but sandflies can still find their way through the cloth and bite - and that's if the soldier has the uniform on in the first place, which is not common during summer nights in the desert. A further complication is that each of the four services has its own uniform, each with a different ability to guard against insects.

In the early 1990s, as the first Gulf War was starting, some services began issuing new uniforms pre-treated with insecticide. This

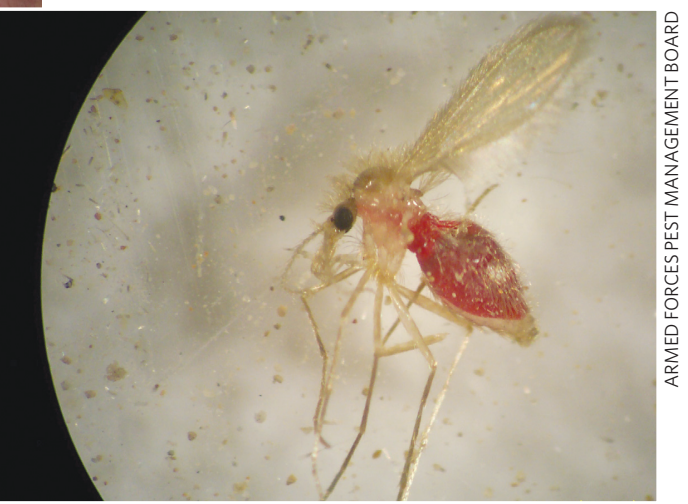




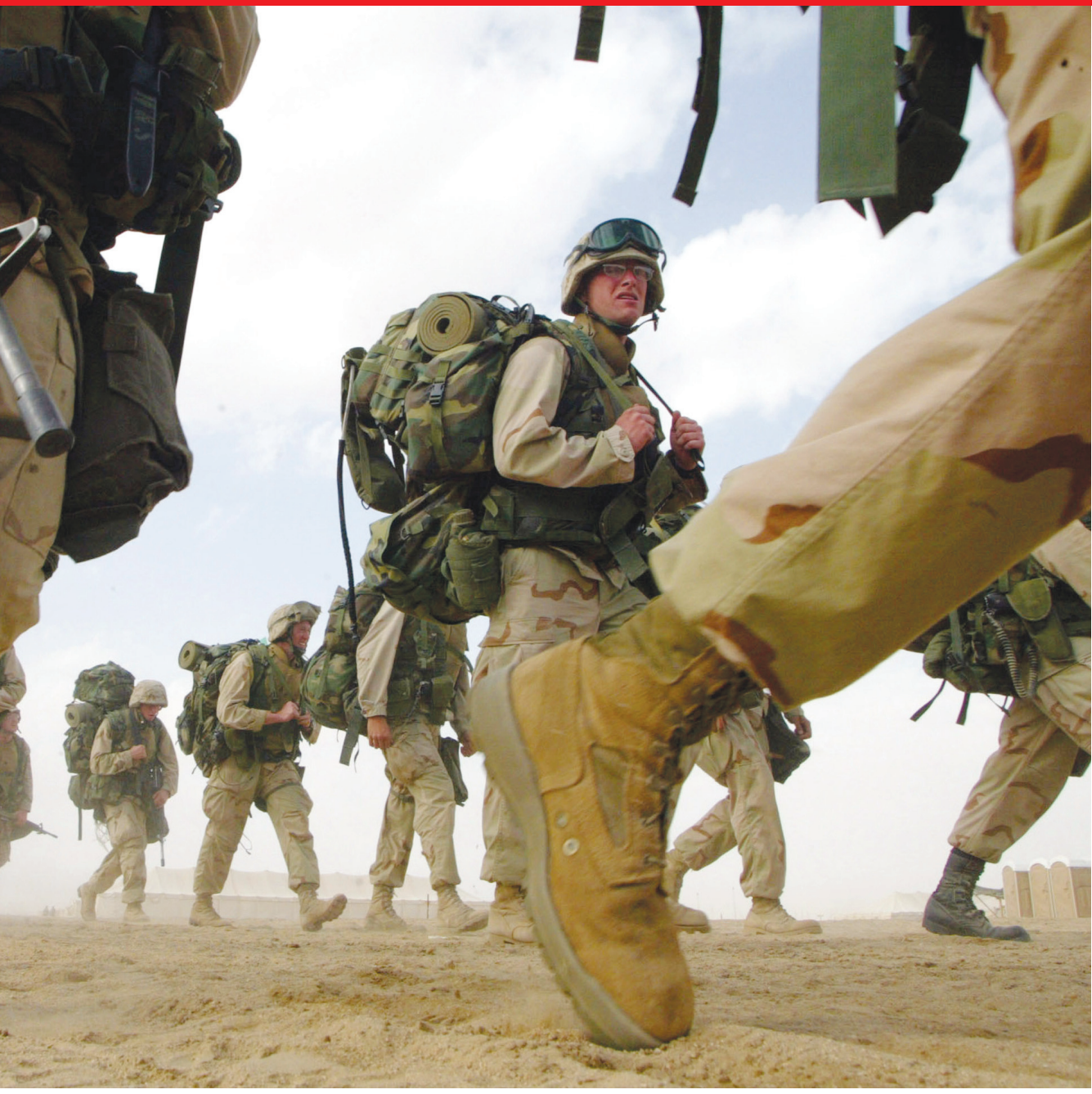

Science is guiding uniform design to prevent troops from insect bites while serving in desert areas.

barrier would be boosted periodically in the field by adding chemicals to the uniform. Then in 2003, a deployment of about 75 marines showed how vulnerable a soldier in uniform can be. Nearly $40 \%$ of the marines stationed in Monrovia, Liberia, during a civil disturbance contracted malaria. That's when marine commanders turned to the USDA centre to identify the uniforms' weakness.

Researchers there realized that the corps put their uniforms through a permanent press treatment to make them look ironed and the creases look sharp. The marines were the only service to do so. They had also switched to a twill fabric from a mixed weave. Those two factors let the mosquitoes through to bite, says Bernier.

\section{New system}

That was enough to get the corps to change their uniforms. "The marines raised the bar," he says. "They wanted to stop 100\% of the biting." Working with USDA researchers and those at the Army Soldier Systems Center at Natick in Massachusetts, the marines launched new uniforms in March 2007. The garments now come pre-treated with a stronger insecticide so as to theoretically not need field treatments during the life of the clothing. Bernier is collecting uniforms from marines in Iraq to see how the new system is working.

One challenge, however, is to not saturate the uniform so heavily with insecticide that it starts to become toxic to the wearer ${ }^{3}$. Another complication is that the Army now treats its rayon/nylon uniforms with a fire retardant, as the earlier version would melt into wounds of those burned in bomb attacks. The question remains: how does that fire retardant interact or otherwise affect insect treatments on the same uniform?

What's more, any changes to uniform designs are costly to implement. Marines go through about 385,000 uniforms a year, the Army 4 million. So beyond uniforms, researchers are looking at new and different methods for protecting soldiers from insects.

One approach is to better identify the chemicals that attract insects to humans, and use those to mask skin against the insects. Bernier's team, for instance, has identified at least three chemical blends that attract insects, based on chemicals that humans emit naturally ${ }^{4}$.

Another approach is to develop entirely new types of insecticides. Chemist Alan Katritzky of the University of Florida in Gaines- ville reported recently on an artificial neural $\breve{u}$ network that they used to screen mosquito repellants ${ }^{5}$. His computer modelling system used past data on mosquito repellency to identify 34 new candidate repellants. When tested in the lab, some of the candidates repelled mosquitoes up to three times as long as DEET.

At Louisiana State University in Baton Rouge, researchers are targeting not just the sandflies but also the rodents in whose burrows the flies live. Scientists are studying a feed mixed with a pesticide (novaluron) for rodents. The pesticide is passed onto immature sandflies when they eat the rodents' faeces ${ }^{6}$. This could help solve another problem: troops bulldozed entire areas where tents were being erected to get rid of sandflies, but more would later pop up from the rodent burrows underneath.

\section{Precision spraying}

Meanwhile, USDA researchers in College Station, Texas, are developing a system in which a small, unmanned helicopter is programmed via a computer to spray a set area from 22:00 to 4:00, key hours for sandfly activity. "We mounted a sprayer and global positioning system (GPS) on an expensive toy helicopter," says USDA agricultural engineer Clint Hoffmann. "You set the helicopter's flight pattern with a computer mouse." Field testing is coming soon, with the first overseas study planned for Egypt.

Even the size of droplets sprayed is receiving scrutiny ${ }^{7}$. If you're trying to hit a flying insect, you want a 25 -micrometre droplet. If you want to cover plants or tents, a 100-micrometre droplet is best. "We have a fairly sophisticated drift model that can track individual droplets - even through aircraft vortices or wakes," Hoffmann says. These systems have shown that the standard methods the military used to trap and kill insects, such as spraying in the early evening when sandflies aren't around, are virtually worthless.

It may take a while for the research to work its way into military consciousness, and eventually on to benefit civilians. But with the way the war is going in Iraq, there could be plenty of time left to learn the lessons. Rex Dalton writes for Nature from San Diego.

1. Coleman, R. E. et al. J. Med. Entomol. 43, 647-662 (2006) 2. Frances, S. P. \& Cooper, R. D. ADF Health 8, 50-56 (2007).

3. Macedo, P. A. et al. J. Toxicol. Environ. Health A 70, 1758-1771 (2007).

4. Bernier, U. R. et al. J. Med. Entomol. 40, 653-656 (2003)

5. Katritzky, A. R. et al. Proc. Natl Acad. Sci. USA 105 7359-7364 (2008)

6. Mascari, T. M. et al J. Med. Entomol. 44, 714-717 (2007).

7. Hoffmann, W. C. et al. J. Am. Mosq. Control Assoc. 23, 315-320 (2007). 